\title{
Promoting Behavioral Change Using Text Messages: A Case Study of Blackberry Farmers in Ecuador
}

\author{
Vanessa D. Carrión-Yaguana ${ }^{1, *} \mathbb{D}$, Jeffrey Alwang ${ }^{2}$ and Victor H. Barrera ${ }^{3}$ \\ ${ }^{1}$ Department of Economics, Universidad de Las Américas, Av. de los Granados E12-41 and Colimes, Quito, EC170125, \\ Ecuador, ${ }^{2}$ Department of Agricultural and Applied Economics, Virginia Tech, 215-I Hutcheson Hall, Blacksburg, VA, \\ 24061, USA and ${ }^{3}$ Instituto Nacional Autónomo de Investigaciones Agropecuarias, Panamericana Sur Km. 1, Sector \\ Cutuglagua, Cantón Mejía, Pichincha, Ecuador \\ *Corresponding author. Email: vanessa.carrion@udla.edu.ec
}

\begin{abstract}
This study measures the effect of text message receipt on behavioral change by Ecuadorean blackberry farmers. We examine whether text messages affect knowledge about specific technologies or serve as reminders to farmers to employ practices as part of their crop management strategy. Drawing from well-known theories of behavioral change, we identify pathways relevant to technology adoption. We then describe results from a randomized experiment and measure the impact of the intervention through these pathways. Results suggest that in the blackberry context, timely text messages remind farmers about recommended practices and increase adoption. Effects on knowledge enhancement are not significant.
\end{abstract}

Keywords: blackberry farming; Ecuador; integrated crop management; randomized control trial; technology adoption; text messages

JEL classifications: Q16; O33

\section{Introduction}

Increases in agricultural productivity can drive overall economic growth and development, and can also reduce poverty and hunger (Pingali, 2007). Productivity growth can imply environmental trade-offs as conventional farming practices can lead to problems with soil and water quality. Integrated crop management (ICM) has emerged as a response to these problems (Kumar and Shivay, 2008). ICM comprises practices combined from the best traditional and modern farming methods for managing soils, water, and pests, and includes integrated pest management (IPM) methods as a subset. ICM involves judicious use of fertilizers and IPM practices to minimize pest-related losses, improve yields and crop quality, conserve soil and water resources, and preserve biodiversity (Brumfield, Rimal, and Reiners, 2000). Since ICM involves a complex "package" of interrelated practices, farmers must be trained in their use prior to adoption. Insufficient training has been recognized as an important cause of limited ICM adoption in the developing world (Palis, Singleton, and Casimero, 2010; Martínez-García, Dorward, and Rehman, 2016).

Substantial effort has gone into developing agricultural training programs to enhance farmers' technical knowledge. Common approaches have been farmer field schools (FFS), field days, extension agent visits, observation visits, and mass media activities. FFS focuses on the transfer of information in a participatory way, involving weekly training sessions during a full crop season (Carrión Yaguana et al., 2016; Feder, Murgai, and Quizon, 2004). Field days are training events held on a working farm designed to provide information about specific topics and give 
participants an opportunity to see the practices as they are being implemented. Extension agent visits involve direct provision of information to farmers.

Literature on FFS highlights impacts on short-term knowledge improvement, decreased pesticide use, and increased productivity (Cole et al., 2002; Godtland et al., 2004; Mauceri et al., 2007). However, there is little evidence of long-term retention of the complex knowledge imparted by FFS training. Furthermore, the adoption of complex agricultural technologies among FFS participants remains low (Akudugu, Guo, and Dadzie, 2012; Beaman et al., 2014; Bonabana-Wabbi, 2002; Carrión Yaguana et al., 2016; Ibrahim, 2013). FFS has also been found to be expensive per person reached (Mauceri et al., 2007; Feder, Murgai, and Quizon, 2004). Field days represent a compromise, costing less compared to FFS to providers and participants and enabling far wider participation. Evidence, however, shows that field day participants do not generally adopt complex technologies (Mauceri et al., 2007).

Growing evidence shows that many supposedly profitable agricultural technologies are not widely adopted. Explanations for lack of adoption include constraints faced by farmers, such as knowledge/information (Drechsel et al., 2005; Drost et al., 1996) and lack of inputs or credit for their purchase (Prudent et al., 2007; De Janvry, 2000); agroecological considerations such as heterogeneous conditions (Deguine and Penvern, 2014); and others.

The behavioral economics literature is rife with examples of behavior that fails to conform to predictions of theory (DellaVigna, 2009). This literature provides hints about why the adoption of certain agricultural technologies is low. More often than not, individuals simplify complex decisions by processing only a subset of information. People fail to make rational choices because they might not think about all their choices or systematically mis-predict how they will feel in the future. Mullainathan and Shafir (2013) argue that scarcity captures individuals' minds and prevents people from making trade-offs using a cost-benefit calculus; simple reminders may overcome such distractions. A final explanation is that most agricultural interventions have focused on increasing farmer knowledge as the only mechanism to induce behavioral change. Other mechanisms can contribute to behavioral change, and their neglect might limit adoption ${ }^{1}$.

We implement a low-cost ${ }^{2}$ intervention that tests whether behavioral factors such as simplified decision-making in the presence of complex technologies or simple reminders for time-sensitive practices influence decision-making. Objectives are to: (1) understand how the receipt of text messages complements training from a farmer field day; and (2) identify the behavioral paths by which text messages influence the adoption of ICM technologies.

This paper tests whether behavioral theory can help complement field days to promote the diffusion of relatively complex ICM technologies. As noted, field days represent a low-cost alternative to FFS, which are widely used in ICM promotion. In a world of increasingly tight budgets for outreach, this information may promote efficient use of resources. While there is some agreement that text messages can help stimulate technology adoption, closer attention to behavioral theory might increase their effectiveness. In the field of e-health, it has been shown that interventions with more behavior change techniques have larger effects compared to those that incorporate fewer techniques (Webb et al., 2010). In this sense, this paper contributes to the literature by examining the factors that predict ICM adoption and how such factors can be implemented in effective behavior change interventions.

The remainder of the paper is organized as follows: Section 2 draws from literature on behavioral change to identify pathways by which text message interventions can influence the

\footnotetext{
${ }^{1}$ Psychological literature describes a dynamic process shaped by interdependent factors that facilitate behavioral change (Michie et al., 2005, 2008; Stern, 1999).

${ }^{2}$ National government and research and development organizations invest resources to promote the adoption of ICM. Since these programs increasingly face resource constraints, low-cost alternatives become more attractive. These interventions provide the opportunity for practitioners to increase adoption of agricultural technologies by using these modalities independently or as complements to other extension methods.
} 
adoption of agricultural technologies in the specific context of blackberry producers in the interAndean valleys of Ecuador. Section 3 describes the study site and the technologies. Sections 4 and 5 explain the intervention and shows how the influence of specific behavioral factors is tested in the context at hand. Section 6 examines the results, and Section 7 concludes.

\section{Theories of behavioral change}

Mechanisms to influence behavioral change can be derived from psychosocial theory. Such theories have commonalities that can be used to explain behavioral change in agriculture. Michie et al. (2005) developed the theoretical domain framework (TDF) to categorize behaviors and their determinants. They identified 12 theoretical domains ${ }^{3}$ that encompass the range of current scientific explanations for human behavior. These can be condensed into three core components: capability, opportunity, and motivation. We focus on capability, which refers to the psychological or physical ability to enact the behavior. Elements of this component are: knowledge; memory, attention, and decision processes; behavioral regulation; and skills.

Capability factors that can generate behavioral change over the course of a brief, low-cost intervention are (1) knowledge and (2) memory, attention, and decision processes. Memory, attention, and decision processes refer to the ability to obtain and retain information and choose among alternatives (Lipworth, Taylor, and Braithwaite, 2013). Research shows that individuals often simplify complex decisions by processing only a subset of information (DellaVigna, 2009). For simplicity, from now on, we will refer to this determinant as limited attention. Knowledge, on the other hand, is important because an individual's understanding of the scientific rationale and procedures associated with a behavior is likely to affect whether she decides to implement it (Lipworth et al., 2013).

\subsection{Reminders, knowledge, and technology adoption}

Limited attention and knowledge can be manipulated within the context of a short intervention as shown in Figure 1. Psychologists agree that the most effective technique to address the knowledge determinant is to provide information regarding the behavior in question and possible outcomes from changes in such behavior. To target limited attention, prompts, triggers, and cues can be used to increase attentiveness (Michie et al., 2008).

The adoption of a farming practice can be thought as knowledge learned and used as intended (Olsen, 1998). Because technologies are imperfectly known, farmers seek information about them before deciding whether to adopt (Conley and Udry, 2010; Feder and Slade, 1984). When learning takes place and returns are found to exceed those of existing technologies, the new information may affect behavior (Foster and Rosenzweig, 2010). Learning occurs through experience, either one's own or that of others (de Janvry, Macours, and Sadoulet, 2017).

Technology uptake is a conscious decision that requires attention. At one point in time, a farmer may have intended to adopt some or all ICM practices. However, at another point in time, those intentions may no longer be contemplated, buried by daily distractions. Prompts, triggers, and cues in the form of reminders can help farmers focus on their environment, and ignore competing stimuli. In other words, reminders directing attention to a particular action should make its execution more likely (Taubinsky, 2014). Timely text messages have been shown to be effective reminders of time-sensitive management practices increasing the adoption of IPM practices in Ecuador (Larochelle et al., 2019). Simple cues have been shown to make people more attentive

\footnotetext{
${ }^{3} \mathrm{~A}$ theoretical domain is a group of related theoretical constructs. The domains identified by Michie et al. (2005) are: knowledge; skills; social/professional role and identity; beliefs about capabilities; beliefs about consequences; motivation and goals; memory, attention, and decision process; environmental context and resources; social influences; emotion; behavioral regulation; and nature of the behaviors.
} 


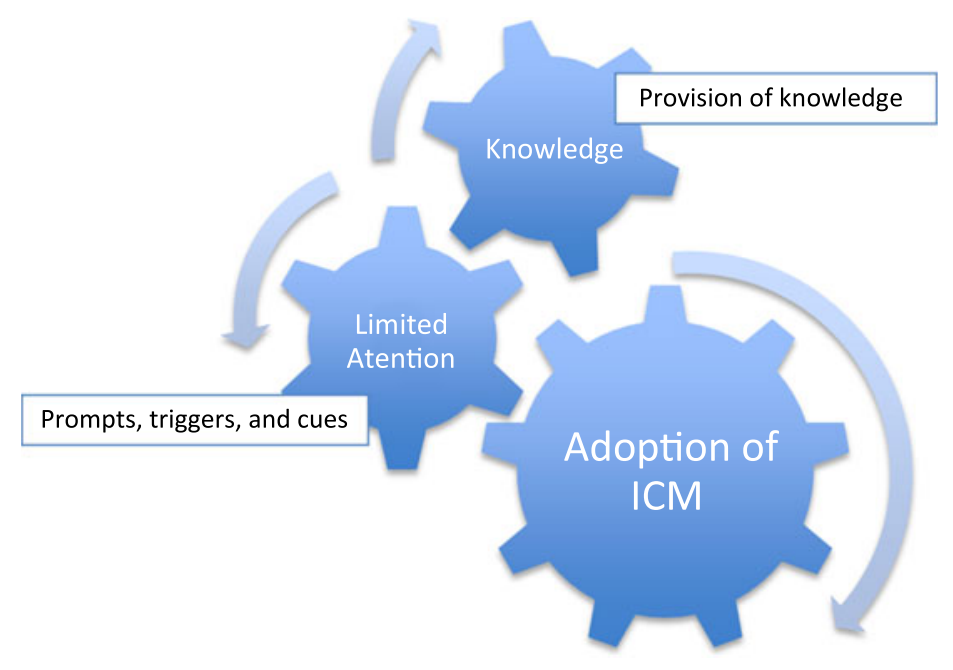

Figure 1. Behavioral change strategies.

Source: Drawing elaborated by the author based on Kageyama et al. (1998).

and increase savings (Ashraf, Karlan, and Yin, 2006; Karlan et al., 2016). In health outcomes, text message reminders can improve compliance with chronic medication regimes (Vervloet et al., 2012) and increase influenza vaccination rates (Stockwell et al., 2012).

\subsection{Text messages as a tool for behavioral change}

The widespread availability of cellphone plans that provide unlimited text messages has resulted in increased use of messaging throughout the world. Mobile phone penetration in developing countries now exceeds $90 \%$ and is projected to grow further (Global System for Mobile Communications Association, 2018). Mobile phone availability in rural areas has increased, opening opportunities for delivering information and reminders to farmers.

Several studies have evaluated the behavioral effects of text message-based interventions and the results are promising (Karlan et al., 2016; Larochelle et al., 2019; Stockwell et al., 2012; Vervloet et al., 2012). The impacts of mobile phones on agriculture have been evaluated from different perspectives. To evaluate cellphones as a means of information provision, Nakasone (2014) conducted a randomized control trial (RCT) in Peru. Farmers were given detailed market price information via SMS corresponding to their main crops. Message recipients obtained higher prices for their products compared to those in the control group. The mechanism behind these effects is information availability. Cole and Fernando (2012) conducted an impact evaluation of the Avaaj Otalo (AO) program among cotton farmers in Gujarat, India. This program used voice messages to push and pull content. Farmers received weekly information and were able to call in to a toll-free hotline and ask questions on topics of interest. Questions were answered by agronomists who delivered advice to farmers via recorded voice messages. Participants were found to increase adoption of the pesticide imidacloprid by $10 \%$.

In an attempt to evaluate cellphones as a means of information and reminder providers, Fafchamps and Minten (2012) implemented an RCT in Maharashtra, India, to assess the impact of price and weather information and crop advice distributed through the SMS. They found a positive but non-significant impact on prices received by farmers, crop losses, and changes in crop varieties. They found no evidence that treated farmers were more likely to adopt the practices recommended through the SMS. Larochelle et al. (2019) conducted an RCT among potato farmers in Carchi, Ecuador. They argue that uncertainty about the benefits of IPM and competing farming 
activities limit IPM adoption. Farmers who received SMS adopted IPM practices at higher rates. Treated farmers also exhibited more knowledge about IPM.

Contradictory findings from these different studies show that outcomes of an intervention depend on its design and context. India's program experienced a rapid expansion following the introduction of the service in 2007-2009. However, during the study period (2009-2010), it showed a stagnation possibly related to a loss of interest on the part of participants. The knowledge determinant could be addressed by providing information regarding the behavior in question and possible outcomes from changes in it. Text messages might not only present information but also help shape a positive attitude towards behavior.

While most of this literature provides evidence of the efficacy of cellphones and text messages on agriculture, often the details of the theory are missing. Hence, there is still need for more research on interventions that comprehensively and accurately map intervention content with theoretical determinants. Such a mapping would allow us to understand which procedures are effective in which contexts and how programs have their effect.

\section{Study site and ICM program}

The increase in demand for blackberry (Rubus glaucus) in the United States and Europe has led to an expansion of area dedicated to the crop in several countries (Badenes and Byrne, 2012). In Ecuador, blackberry farming occupies around 5,000 hectares and is grown by nearly 15,000 small- and medium-sized farmers in the Sierra region (Galarza et al., 2016). Blackberry has been traditionally cultivated in Bolivar, Cotopaxi, and Tungurahua Provinces, and is now becoming a promising export crop (Alwang et al. 2019). However, blackberry yields are low, ${ }^{4}$ mainly due to a high incidence of insects and diseases, ${ }^{5}$ moisture stress, and poor crop management (Delgado Orellana, 2012). Yields average $3 \mathrm{~kg}$ per plant per year, far below the $5 \mathrm{~kg}$ per plant per year potential yield (Espín Chico, 2013). Among the most damaging insect pests are mites, aphids, and spider mites. Common diseases are botrytis fruit rot (Botrytis cinerea), powdery mildew (Oidium sp.), downy mildew (Peronospora sparsa), wilt (Verticilium sp.), and blackberry rosette (Cercosporella rubi) (Yumbo and Elvia, 2014).

Since many farmers do not use pesticides or implement other modern management methods for blackberry, scientists of the National Autonomous Institute of Agricultural Research (INIAP) and the USAID-sponsored IPM Innovation Lab developed and tested several non-IPM and IPM practices for the control of common insect pests and diseases in blackberry.

Non-IPM practices do not have a particular focus on pest management. They aim to keep plants healthy and maximize yields and fruit quality. Examples of non-IPM practices are pruning, using a simple string trellis, and harvesting at the proper stage of maturity. IPM includes cultural ${ }^{4}$ and chemical practices, where chemicals used in IPM are less toxic than conventional ones.

Examples of IPM practices recommended by the research are use of bordeaux mixture (a fungicide and insecticide mixture of slaked lime [calcium hydroxide] and copper sulfate), fertilizers and low-toxicity pesticides, disposal of pruned plant material from the field, and disinfection of tools between uses. These practices were developed, validated, and calibrated for local conditions during 3 years of applied research. They were combined into a package and made available to farmers in March 2013. Biopesticides were not integrated in the package because in Ecuador there are few available for blackberry. Biopesticides face a high competition from synthetic pesticides since they are produced on a small scale at a relatively high cost.

Information from test plots shows that, given prevailing prices, the average net returns for a conventional blackberry production system is about $\$ 2,550$ per ha in the first year, $\$ 8,492$ in the second year, and $\$ 11,242$ in the third year, while expected returns under the ICM regime are

${ }^{4}$ IPM cultural controls are practices that reduce pest establishment, reproduction, dispersal, and survival.

${ }^{5}$ This result is derived from the following calculation: 100 (1.12-1). 
$\$ 3,760, \$ 11,734$, and $\$ 15,734$, respectively. Blackberry plants continue fully productive more than 15 years under good management (Martinez, 2016).

In order to evaluate the effectiveness of text messages as information and task reminders, an RCT was conducted in Tungurahua and Bolivar provinces. RCTs, when feasible, are the preferred method for identifying the causal effects of interventions. Since random assignment equalizes treatment and control groups on all observable and unobservable variables, RCTs give confidence that differences in outcomes between treatment and control are actually caused by the treatment (Armijo-Olivo, Warren, and Magee, 2009; Duflo, Glennerster, and Kremer, 2007). We distinguish between the effects of intervention on adoption of non-IPM and IPM practices. This distinction is important because the nature of innovation can impact its adoption (Kimberly and Evanisko, 1981).

The intervention consisted of training farmers in blackberry ICM during field day events followed up with text messages sent through the blackberry growing cycle. Three farmer field days were held in February 2014, two in Tungurahua and one in Bolivar. Blackberry farmers were invited to attend through a radio advertising campaign and contacts with extension agents from the Ministry of Agriculture. While attendance at the field day is not random, participation in the subsequent text message intervention was randomly assigned. The field days consisted of three stations where technicians demonstrated specific blackberry management practices: (1) preparation of bordeaux mixture, (2) proper pruning techniques, and (3) building a simple string trellis with just one twine. Farmers were organized into small groups to tour the demonstrations, and each participant received a companion brochure with detailed information on a complete set of blackberry ICM practices. All extension workers who collaborated on the project participated in the field days. They have higher education degrees in agriculture with practical work experience of more than 10 years.

The objective of demonstrating preparation and application of the bordeaux mixture was to teach methods for preparing chemical compounds. This knowledge would be useful when farmers need to prepare compounds, part of the ICM regime. Instructions were designed to be easy to follow even for those with little prior experience. The pruning station provided training on pruning techniques. Blackberry plants need to be pruned at various stages of growth. Three of the five recommended non-IPM practices refer to pruning. Trellising plants is necessary because trailing varieties are commonly planted in Ecuador. Scientists recommend using a string trellis with just one twine.

Aggregate attendance at the field days was 422 farmers from 77 villages. As part of a short baseline survey during the field day, participants were asked about mobile phone ownership, capability to receive text messages, socioeconomic characteristics (gender, age, and position in the family), and stage of their blackberry. The latter allowed us to distinguish between farmers with fully grown blackberry crops from those who just planted or had an intention to plant.

To be eligible for the intervention (receipt of text messages), a field day participant had to be literate, own a mobile phone capable of receiving text messages, and be growing blackberry. Two hundred ninety-two farmers from 68 villages were eligible to participate in the free text message program. The treatment was randomized at the village level to avoid potential problems of withinvillage spillovers (Duflo et al., 2007). Thirty-two villages were assigned to the treatment group. The treated and control groups consisted of 154 and 138 farmers, respectively.

The blackberry fruit growing season in Bolivar and Tungurahua begins in March when the moisture is sufficient to guarantee a good harvest, which begins in May or June. Following the February field days, eligible farmers from treated villages received 33 text messages informing them about ICM practices. Messages provided ICM information and reminded recipients of tasks to optimize blackberry profits. An example of a text message is: "remember to dispose of pruned plant material to prevent spread of diseases." The first part of the message provides the reminder: "remember to dispose of pruned plant material", and the second part provides information: "to prevent spread of diseases." These messages were sequenced according to the blackberry 
production calendar and also referred to the page of the brochure where more detailed information could be found about the task mentioned in the message.

Three messages were sent per week for 11 weeks. Messages were concise and easy to understand. No one who was offered the text message service declined to participate.

A follow-up survey was administered to participants at their farms following the intervention (June and July 2014). It contained four modules and included socioeconomic information, blackberry production data such as cultivated area and yields, and questions about ICM adoption. It also included an ICM knowledge test. Due to incomplete or incorrect addresses, enumerators were able to locate 229 farmers in 62 villages, of which 125 were intended to be treated.

\section{Methods}

The ICM information in the SMS focused on agricultural practices tailored to blackberry farming in the intervention areas. Over the course of the intervention, farmers received advice on 5 non-IPM practices and 15 IPM practices (Table 1 ) that required the use of 20 different chemical and organic fertilizers and low-toxicity pesticides (Table 2).

Ideally, the impact analysis should focus on differences in profits, because they correspond best to the overall economic impact of the interventions. However, we did not gather cost estimation information because the collection of such information would have required a far more involved survey. The analysis instead focuses on the impact on adoption of practices.

The adoption of technologies can be described as discrete (a farmer either is, or is not, an adopter) or continuous. We consider only the latter measures of adoption because partial adoption of ICM packages is the norm (Arslan et al., 2014). The adoption of non-IPM practices refers to the number of practices adopted out of five non-IPM recommended practices. To measure the adoption of IPM practices, we aggregate the adoption of cultural IPM practices (0-4) and the raw count of recommended low-toxicity pesticides (0-3) and fertilizers used (0-4).

Because the treatment is randomized, the impact of intervention can be estimated by a simple comparison of mean adoption rates for treatment and control groups. This comparison is only possible when balance between intervention and control groups is achieved. Balance means there are no significant differences in means of variables by treatment group and indicates that the randomization process worked (Duflo et al., 2007). In addition to the comparison of means, impact is also estimated in a regression framework. The use of regression reduces idiosyncratic variation and increases precision (Glennerster and Takavarasha, 2013). For a continuous measure of adoption of non-IPM practices, a Poisson MLE analysis is the natural first step. Poisson uses the exponential mean function ensuring that the predicted values of the outcome variable are never negative (Wooldridge, 2006). Formally, we estimate:

$$
\begin{gathered}
y_{n-I P M i}=\exp \left(\alpha_{0}+\alpha_{1} T_{i}+\alpha_{2} T_{1 i}+X_{i} \alpha_{3}+e_{i}\right) \\
y_{I P M_{i}}=\exp \left(\alpha_{0}+\alpha_{1} T_{i}+\alpha_{2} T_{1 i}+X_{i} \alpha_{3}+v_{i}\right)
\end{gathered}
$$

where $y_{n-I P M_{i}}$ and $y_{I P M_{i}}$ are variables reflecting the adoption of non-IPM and IPM practices by the $i$ th household, respectively. The key independent variable $T_{i}$ is a dummy indicating ITT. Since a significant percentage of treated farmers did not receive text messages due to technical problems related to data systematization and verification errors (discussed in the next section), we include a dummy variable $T_{1 i}$ to account for the fact that farmers in this group are less likely to adopt ICM. $X$ is a vector of observed socioeconomic characteristics including age, education, and gender of the farmer, household size, wealth, blackberry farming experience, and area per capita planted with blackberry; $e_{i}$ and $v_{i}$ are random error terms clustered by village, and assumed to be independent across clusters but correlated within clusters. The wealth index was created using principal component analysis (PCA) based on the ownership of selected household assets (TV set, refrigerator, microwave, washer, computer, landline, cellphone, home drinking water, toilet inside the house, 
Table 1. Non-IPM recommended practices and their uses

\begin{tabular}{ll}
\hline Practices & Helpful for \\
\hline Pruning during production season & Keeping plants healthy and increasing fruit yield \\
\hline Pruning during fruiting season & Keeping plants healthy and increasing fruit yield \\
\hline Cut off unproductive branches & Keeping plants healthy and increasing fruit yield \\
\hline Building a simple string trellis with one twine & Supporting a growing blackberry plant \\
\hline Harvesting at the right stage of maturity & Ensuring the best taste and quality \\
\hline
\end{tabular}

Table 2. IPM practices and their uses

\begin{tabular}{|c|c|}
\hline Cultural practices & Helpful for \\
\hline Disposal of pruned plant material from the field & Preventing the spread of diseases that reduce yields \\
\hline Making and applying organic homemade fertilizer & $\begin{array}{l}\text { Lowering costs (homemade fertilizers are more cost- } \\
\text { efficient than commercial products) }\end{array}$ \\
\hline Disinfect tools between uses & Preventing the spread of plant diseases \\
\hline Elimination of weeds & $\begin{array}{l}\text { Reduce insect problems and competition with } \\
\text { blackberry }\end{array}$ \\
\hline Phytosanitary controls & Problem \\
\hline $\begin{array}{l}\text { Preparation of bordeaux mixture }(1 \mathrm{~kg} \text { slaked lime }+ \\
1 \mathrm{~kg} \text { copper sulfate in } 200 \text { l of water) }\end{array}$ & Fungi and mites \\
\hline $1 / 2 \mathrm{~kg}$ of copper $+1 / 2 \mathrm{~kg}$ of sulfur in $200 \mathrm{l}$ of water & Powdery mildew \\
\hline Spray $1.5 \mathrm{ml}$ of potassic phosphite per liter of water & Downy mildew \\
\hline $\begin{array}{l}\text { Spray } 1 \mathrm{ml} \text { of azoxystrobin (brand name: Amistar) } \\
\text { per liter of water }\end{array}$ & Downy mildew \\
\hline $\begin{array}{l}\text { Spray } 1 \mathrm{ml} \text { of penconazole (brand name: Topas) } \\
\text { per liter of water }\end{array}$ & Powdery mildew \\
\hline $\begin{array}{l}\text { Spray } 1 \mathrm{ml} \text { of difenoconazole (brand name: Score) } \\
+1 \mathrm{ml} \text { of dicofol (brand name: Acarin) per liter of water }\end{array}$ & Downy mildew, powdery mildew, and mites \\
\hline \multicolumn{2}{|l|}{ Foliar fertilization } \\
\hline \multicolumn{2}{|l|}{ Spray $1 \mathrm{ml}$ of boron chelates per liter of water } \\
\hline \multicolumn{2}{|l|}{ Spray iron chelates + zinc chelates 1 cc per liter of water } \\
\hline \multicolumn{2}{|l|}{ Spray $1 \mathrm{ml}$ of calcium chelates per liter of water } \\
\hline \multicolumn{2}{|l|}{ Soil fertilization } \\
\hline \multicolumn{2}{|c|}{$100 \mathrm{~g}$ of $18-46-00$ fertilizer $+100 \mathrm{~g}$ of urea $+2 \mathrm{~kg}$ of organic homemade fertilizer per plant } \\
\hline $100 \mathrm{~g}$ of nitrogen $+150 \mathrm{~g}$ of potassium $+2 \mathrm{~kg}$ of organ & ic homemade fertilizer per plant \\
\hline
\end{tabular}

motorcycle, car, and cattle). A cluster is defined as a group of interdependent farmers who operate in a geographically concentrated area.

Age, education, experience, and gender are characteristics often included as determinants of adoption of agricultural and IPM technologies. When tested empirically in the IPM literature, the impact of age on adoption has mixed results. On the one hand, older farmers over time have 
gained farming knowledge and experience and are better able to evaluate technology information compared to younger farmers (Mugisha et al., 2005). On the other hand, theories that model adoption decision using risk contend that age is negatively correlated with adoption as risk tolerance decreases as a farmer grows older (Fernandez-Cornejo, 1998; Mauceri et al., 2007). To allow for a non-linear relationship between adoption and age, we include age and age-squared. Education is expected to be positively related to adoption because more educated farmers understand and respond better to new technologies (Fernandez-Cornejo, 1998). The effect of blackberry farming experience is anticipated to be positive because more experienced farmers are more likely to be better able to access new technology (Blake et al., 2007; Khanna, Epouhe, and Hornbaker, 1999). In most contexts, age and farming experience are highly correlated. However, in our study, this is not the case since blackberry is a relatively new crop in the area.

Gender refers to the sex of the participant. This person was identified at the field day as one who plays the leading role in blackberry production. There are a high percentage of women blackberry farmers in Ecuador. It was observed during the fieldwork that female farmers showed special interest in blackberry ICM. For this reason, we expect the gender variable $(1=$ female and $0=$ male) to positively affect adoption.

Area per capita planted with blackberry, household size, and wealth are expected to have positive effects on adoption. Farmers operating relative large farms can devote part of their land to try new technologies (Cuyno, Norton, and Rola, 2001; Feder, Just, and Zilberman, 1985). We expect a positive effect of household size because large families have more labor available to perform on-farm activities (Bonabana-Wabbi, 2002), enabling farmers to adopt practices requiring extra labor such as the application of organic homemade fertilizer and elimination of weeds. The wealth index is anticipated to have a positive effect, especially if the innovation requires cash input purchases such as recommended low-toxicity pesticides and fertilizers (Chaves and Riley, 2001; Teklewold, Kassie, and Shiferaw, 2013).

Additionally, we evaluate the impact of the intervention on knowledge. To measure knowledge, each farmer was given a maximum score of 5 points based on correct responses to a five-question knowledge test. The questions referred to information presented at the field day and reinforced through the text messages. A Poisson regression is used for estimation:

$$
y_{K i}=\exp \left(\gamma_{0}+\gamma_{1} T_{i}+\gamma_{2} T_{1 i}+W_{i} \gamma_{3}+e_{i}\right)
$$

where the knowledge score variable $y_{K i}$ is a function of the treatment $\left(T_{i}\right.$ and $\left.T_{1 i}\right)$, and a vector of control variables $W$ that includes age, education and experience. These factors have been widely recognized as relevant for knowledge acquisition (Feder and Slade 1984; Luh, Jiang, and Chien, 2014; Wozniak, 1993). The term $e_{i}$ is a random error, assumed to be independent across clusters but correlated within clusters.

\section{Results}

We start our analysis using the intention-to-treat (ITT) principle. In ITT analysis, units randomly assigned to receive treatment are compared to those assigned to the control regardless of whether they completed the intervention (Armijo-Olivo et al., 2009). ITT analysis is widely used to analyze experiments because it involves the purest experimental comparison. However, when units assigned to the treatment group do not receive the treatment, ITT results in a negatively biased treatment effect estimate (Dunning and Hyde, 2008).

In this study, 29 ITT farmers reported not receiving the text messages, raising the question of whether these should be regarded as non-compliers. In the standard language of RCTs, noncompliers refers to participants who did not consistently exhibit the behavior required by the treatment under examination (Peugh et al., 2017). Within this group, we were able to distinguish two types of farmers who did not receive the text messages: (1) non-compliers-non-recipients due to individual behavior; and (2) treatment non-recipients-non-recipients due to technical 
problems related to data systematization and verification errors. The first group includes eight farmers whose phones were lost or damaged or who changed phone numbers. These farmers represent non-compliance that most likely occurs in every intervention of this kind and is difficult to overcome. The second group includes 21 farmers whose phone numbers were mistyped, those who gave a phone number belonging to a relative or friend, and those who did not know how to open text messages. This is not non-compliance in the traditional sense and is a barrier to treatment that might be easily overcome. One possibility would be to send a text message at the moment of enrollment to verify that information was recorded correctly and that the farmer knows how to operate the mobile phone.

To evaluate the impact of the intervention, we also estimate an adjusted version of ITT where the 21 non-recipients due to technical problems related to data systematization and verification errors are excluded from the calculation. The adjusted ITT analysis removes the unintended effect of a controllable non-compliance. As stated by Dunn et al. (2003), "If we are really interested in assessing the size of the benefit of receipt of treatment, as opposed to merely the offer of it, then our statistical analysis needs to proceed beyond ITT."

It may be argued that this estimation might deliver biased estimates because recipients and non-recipients (including non-compliers) may no longer be balanced on observed and unobserved characteristics. To rule out this possibility, we conduct a check of summary statistics of different groups (non-recipients due to individual behavior, non-recipients associated with technical problems due to data systematization and verification errors, and control group). Non-compliance is likely to be random because there are no statistically significant differences between the groups. Hence, our results are not biased by exclusion of these observations.

\subsection{Mean comparison analysis}

\subsubsection{Household and farm characteristics}

The socioeconomic characteristics of farmers in the treatment and control groups are presented in Table 3. For columns (1), (2), (3), (5), and (6), the mean and standard deviations of each variable are reported. In columns (4) and (7), we present the mean differences between control and treatment groups.

Statistics obtained using ITT analysis are presented in columns 2-4. Since treatment assignment was random, we expect to find statistical balance across the control and treatment groups. This balance was largely achieved. The only significant difference between the groups is that the control included 16 percentage point fewer women, a difference that is significant at the $10 \%$ level. This pretreatment difference is relatively minor and is not likely to be indicative of a systematic bias. The last three columns show the statistics for the adjusted ITT analysis. The difference between the percentages of women in the adjusted ITT and control group is still positive and large. The average farmer is about 44 years old and has an eighth grade education. She has 10 years of blackberry farming experience, and her blackberry plot measures 0.67 hectare.

\subsubsection{ICM adoption and knowledge}

ICM adoption and knowledge scores of farmers in the treatment and control groups are presented in Table 4. ITT was calculated using the following regression: $Y_{i}=$ treatment $+\mu_{i}$. Estimates are not significant at conventional levels. Under the adjusted ITT analysis, we find that farmers who received text messages have a higher adoption of IPM practices by 0.58 practice, a difference that is significant at the $10 \%$ level. IPM includes cultural practices, adoption of fertilizers, and adoption of pesticides. The raw count of recommended low-toxicity pesticides used by farmers in the treatment group is, on average, 0.76 compared to 0.47 in the control group. This result provides evidence that the intervention has been effective in increasing the use of recommended 
Table 3. Household and farm characteristics of sampled blackberry farmers in Ecuador, 2014

\begin{tabular}{|c|c|c|c|c|c|c|c|}
\hline \multirow[b]{2}{*}{ Variable } & \multirow[b]{2}{*}{ Overall (1) } & \multicolumn{3}{|c|}{ ITT } & \multicolumn{3}{|c|}{ Adjusted ITT } \\
\hline & & Treatment (2) & Control (3) & Difference (4) & Treatment (5) & Control (6) & Difference (7) \\
\hline $\mathrm{N}$ & 229 & 125 & 104 & 229 & $104^{\mathrm{a}}$ & 104 & 208 \\
\hline Age (years) & $43.58(13.13)$ & $44.45(13.19)$ & $42.53(13.05)$ & $1.92(2.05)$ & $44.07(13.19)$ & $42.53(13.05)$ & $1.54(2.02)$ \\
\hline Education (years) & $7.52(3.79)$ & $7.55(3.62)$ & $7.47(3.99)$ & $0.08(0.71)$ & $7.83(3.66)$ & 7.47 (3.99) & $0.35(0.73)$ \\
\hline Secondary education ( 1 = secondary education) & $0.35(0.48)$ & $0.33(0.47)$ & $0.38(0.49)$ & $-0.05(0.08)$ & $0.36(0.48)$ & $0.38(0.49)$ & $-0.03(0.08)$ \\
\hline Gender ( 1 = female) & $0.38(0.49)$ & $0.45(0.50)$ & $0.29(0.46)$ & $0.16^{\star \star}(0.08)$ & $0.43(0.50)$ & $0.29(0.46)$ & $0.14^{\star}(0.08)$ \\
\hline Household size (count) & $4.49(1.83)$ & $4.38(1.90)$ & $4.62(1.75)$ & $-0.23(0.25)$ & $4.49(1.88)$ & $4.62(1.75)$ & $-0.13(0.23)$ \\
\hline Wealth index & $0.00(1.65)$ & $0.05(1.74)$ & $-0.062(1.55)$ & $0.11(0.27)$ & $0.06(1.79)$ & $-0.06(1.55)$ & $0.12(0.30)$ \\
\hline Farming experience (years) & $25.81(14.09)$ & $26.42(14.54)$ & $25.08(13.57)$ & $1.34(2.35)$ & $25.80(14.23)$ & $25.08(13.57)$ & $0.72(2.19)$ \\
\hline Blackberry farming experience (years) & $10.46(8.84)$ & $10.76(8.90)$ & $10.09(8.79)$ & $0.68(1.27)$ & $10.25(8.41)$ & $10.09(8.79)$ & $0.16(1.37)$ \\
\hline Area per capita planted with blackberry (ha) & $0.15(0.16)$ & $0.13(0.14)$ & $0.18(0.18)$ & $-0.05(0.03)$ & $0.13(0.14)$ & $0.18(0.18)$ & $-0.05^{\star}(0.03)$ \\
\hline
\end{tabular}

${ }^{a}$ Adjusted ITT excludes 21 non-recipients due to technical problems related to data systematization and verification.

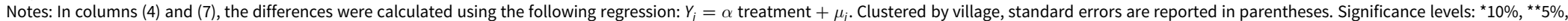
and ${ }^{\star \star *} 1 \%$.

Source: Regression results from study. 
Table 4. ICM adoption and ICM knowledge-intention to treat (ITT), adjusted ITT ${ }^{\mathrm{a}}$

\begin{tabular}{|c|c|c|c|c|c|c|}
\hline \multirow[b]{2}{*}{ Variable } & \multicolumn{3}{|c|}{ ITT } & \multicolumn{3}{|c|}{ Adjusted ITT } \\
\hline & $\begin{array}{l}\text { Treatment } \\
\text { (1) }\end{array}$ & $\begin{array}{c}\text { Control } \\
(2)\end{array}$ & $\begin{array}{l}\text { Difference } \\
\text { (3) }\end{array}$ & $\begin{array}{l}\text { Treatment } \\
\text { (4) }\end{array}$ & $\begin{array}{l}\text { Control } \\
\text { (5) }\end{array}$ & $\begin{array}{l}\text { Difference } \\
\quad(6)\end{array}$ \\
\hline Sample size: 229 & 125 & 104 & 229 & $104^{\mathrm{a}}$ & 104 & 200 \\
\hline $\begin{array}{l}\text { Adoption of non-IPM practices } \\
\text { (number) }\end{array}$ & $3.29(0.97)$ & $3.11(1.11)$ & $0.18(0.15)$ & $3.33(0.97)$ & $3.11(1.11)$ & $0.22(0.15)$ \\
\hline Adoption of IPM practices (number) & $4.33(1.81)$ & $3.93(1.79)$ & $0.40(0.32)$ & $4.51(1.85)$ & $3.93(1.79)$ & $0.58^{\star}(0.33)$ \\
\hline Adoption of IPM cultural practices & $2.53(1.15)$ & $2.29(0.98)$ & $0.24(0.22)$ & $2.58(1.17)$ & $2.29(0.98)$ & $0.29(0.23)$ \\
\hline $\begin{array}{l}\text { Adoption of fertilizers (raw count of } \\
\text { recommended fertilizers used) }\end{array}$ & $1.14(0.83)$ & $1.17(0.89)$ & $-0.03(0.11)$ & $1.17(0.86)$ & $1.17(0.89)$ & $0.00(0.13)$ \\
\hline $\begin{array}{l}\text { Adoption of pesticides (raw count of } \\
\text { recommended low-toxicity pesticides } \\
\text { used) }\end{array}$ & $0.66(0.71)$ & $0.47(0.61)$ & $0.18(0.11)$ & $0.76(0.72)$ & $0.47(0.61)$ & $0.29^{\star \star}(0.12)$ \\
\hline $\begin{array}{l}\text { Knowledge (number of correct } \\
\text { answers out of five) }\end{array}$ & $2.98(1.25)$ & $2.83(1.19)$ & $0.15(0.22)$ & $3.02(1.27)$ & $2.83(1.19)$ & $0.19(0.23)$ \\
\hline
\end{tabular}

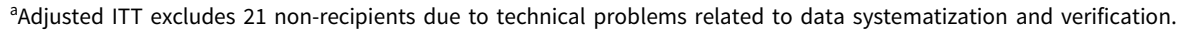

Notes: For columns (1), (2), (4), and (5), the means and standard deviations of each variable in the treatment and control groups are reported. In columns (3) and (6), the differences were calculated using the following regression: $Y_{i}=\alpha$ treatment $+\mu_{i}$. Clustered standard errors are reported in parentheses. Significance levels: ${ }^{\star} 10 \%,{ }^{\star \star} 5 \%$, and ${ }^{\star \star \star} 1 \%$.

low-toxicity pesticide products, less harmful alternatives to toxic chemicals currently used. The effect of the intervention on non-IPM practices is not significant.

As discussed in our theory of behavioral change, this intervention targeted two determinants of behavior: knowledge and limited attention. It aimed to increase the adoption of ICM practices among blackberry farmers by the provision of information, alongside reminders. Thus, the increased adoption rate of cultural ICM practices (Table 4) is expected to be caused by knowledge building and reminder effects. To further validate these results, we created a knowledge score, which measures the number of correctly answered knowledge questions. If text messages have a positive impact on the knowledge score, this implies a knowledge-building effect. If text messages have no impact on the knowledge score, we can infer that messages worked only by reminding farmers to engage in ICM practices.

Mean comparisons show no difference in the adoption of non-IPM practices and knowledge by receipt of treatment. To further understand these results, it is important to evaluate the adoption of individual cultural practices (Table 5) and mean differences in knowledge, question by question (Table 6). Statistically significant differences in adoption were found in one of five non-IPM practices and two of four IPM cultural practices: (1) remove unproductive branches, (2) dispose of pruned plant material, and (3) disinfect tools between uses. The intervention increases adoption of these practices by 13, 20, and 13 percentage points, respectively. These differences can be attributed to the receipt of text messages.

For knowledge questions, we only find a significant difference for the question about disposal of pruned material, which is related to the IPM cultural practice mentioned above. This practice has the highest adoption rate. This result indicates that, at least for this practice, text messages had a knowledge-building effect. It is worth noting, however, that there is not a one-to-one correspondence between knowledge questions and non-IPM and cultural IPM practices. Hence, we cannot verify whether the intervention had a knowledge-building effect for each of the nine non-IPM and cultural IPM practices.

The adoption of agricultural innovations is a dynamic process and depends on a range of factors. Time, resources, risk aversion, topography, climate, variation in soils, technology complexity, 
Table 5. Mean comparison of adoption of non-IPM and IPM cultural individual practices by treatment group

\begin{tabular}{|c|c|c|c|c|c|}
\hline ICM practices & $\begin{array}{l}\text { Intended-to-treat } \\
\text { (ITT) group (1) }\end{array}$ & $\begin{array}{l}\text { Treated } \\
\text { group (2) }\end{array}$ & $\begin{array}{l}\text { Control } \\
\text { group (3) }\end{array}$ & $\begin{array}{c}\text { ITT } \\
\text { (difference) (4) }\end{array}$ & $\begin{array}{l}\text { Adjusted ITT } \\
\text { (difference) (5) }\end{array}$ \\
\hline \multicolumn{6}{|l|}{ Non-IPM practices } \\
\hline Sample size: 229 & 125 & $104^{\mathrm{a}}$ & 104 & & \\
\hline $\begin{array}{l}\text { Pruning during production } \\
\text { season }\end{array}$ & $0.96(0.20)$ & $0.96(0.19)$ & $0.95(0.21)$ & $0.01(0.03)$ & $0.01(0.03)$ \\
\hline $\begin{array}{l}\text { Pruning during fruiting } \\
\text { season }\end{array}$ & $0.56(0.50)$ & $0.60(0.49)$ & $0.55(0.50)$ & $0.01(0.09)$ & $0.05(0.08)$ \\
\hline $\begin{array}{l}\text { Cut off unproductive } \\
\text { branches }\end{array}$ & $0.85(0.36)$ & $0.88(0.33)$ & $0.72(0.45)$ & $0.13^{\star \star}(0.06)$ & $0.15^{\star \star}(0.05)$ \\
\hline $\begin{array}{l}\text { Building a simple string } \\
\text { trellis with one twine }\end{array}$ & $0.51(0.50)$ & $0.52(0.50)$ & $0.48(0.50)$ & $0.03(0.07)$ & $0.04(0.07)$ \\
\hline $\begin{array}{l}\text { Harvesting at the right stage } \\
\text { of maturity }\end{array}$ & $0.41(0.49)$ & $0.38(0.49)$ & $0.40(0.49)$ & $0.01(0.9)$ & $-0.03(0.10)$ \\
\hline \multicolumn{6}{|l|}{ IPM cultural practices } \\
\hline $\begin{array}{l}\text { Disposal of pruned plant } \\
\text { material from the field }\end{array}$ & $0.54(0.50)$ & $0.52(0.50)$ & $0.34(0.47)$ & $0.20(0.09)$ & $0.18^{\star}(0.10)$ \\
\hline $\begin{array}{l}\text { Making and applying organic } \\
\text { homemade fertilizer }\end{array}$ & $0.62(0.49)$ & $0.63(0.49)$ & $0.65(0.48)$ & $-0.04(0.08)$ & $-0.03(0.08)$ \\
\hline $\begin{array}{l}\text { Disinfection of tool between } \\
\text { uses }\end{array}$ & $0.50(0.50)$ & $0.53(0.50)$ & $0.38(0.49)$ & $0.13(0.08)$ & $0.15^{\star}(0.09)$ \\
\hline Elimination of weeds & $0.87(0.34)$ & $0.90(0.30)$ & $0.92(0.27)$ & $-0.05(0.06)$ & $-0.02(0.05)$ \\
\hline
\end{tabular}

${ }^{a}$ Adjusted ITT excludes 21 non-recipients due to technical problems related to data systematization and verification.

Notes: For columns (1), (2), and (3), the means and standard deviations (in parenthesis) of each cultural practice in the treatment and control

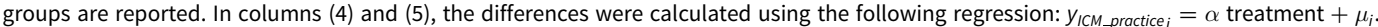
Clustered standard errors are reported in parentheses. Significance levels: ${ }^{\star} 10 \%,{ }^{\star \star} 5 \%$, and ${ }^{\star \star \star} 1 \%$.

Table 6. Mean comparison of knowledge of ICM individual questions by treatment group

\begin{tabular}{|c|c|c|c|c|c|}
\hline ICM knowledge questions & $\begin{array}{l}\text { Intended-to- } \\
\text { treat (ITT) } \\
\text { group (1) }\end{array}$ & $\begin{array}{l}\text { Treated } \\
\text { group (2) }\end{array}$ & $\begin{array}{l}\text { Control } \\
\text { group (3) }\end{array}$ & $\begin{array}{c}\text { ITT } \\
\text { (difference) (4) } \\
\end{array}$ & $\begin{array}{c}\text { Adjusted ITT } \\
\text { (difference) } \\
\text { (5) }\end{array}$ \\
\hline Sample size: 229 & 125 & $104^{\mathrm{a}}$ & 104 & & \\
\hline $\begin{array}{l}\text { Recognize the best stage of maturity of } \\
\text { blackberries for harvesting }\end{array}$ & $0.68(0.47)$ & $0.70(0.46)$ & $0.72(0.45)$ & $0.04(0.07)$ & $-0.02(0.06)$ \\
\hline $\begin{array}{l}\text { Knows the frequency of harvesting } \\
\text { according to plot altitude }\end{array}$ & $0.56(0.50)$ & $0.61(0.49)$ & $0.55(0.50)$ & $0.01(0.08)$ & $0.05(0.08)$ \\
\hline $\begin{array}{l}\text { Knows that the disposal of pruned } \\
\text { material is intended to prevent spread of } \\
\text { diseases }\end{array}$ & $0.54(0.50)$ & $0.55(0.50)$ & $0.34(0.47)$ & $0.20^{\star \star}(0.09)$ & $0.18^{\star}(0.10)$ \\
\hline $\begin{array}{l}\text { Knows that organic homemade } \\
\text { fertilizer has to be applied after } \\
\text { verifying there are no insects present }\end{array}$ & $0.62(0.49)$ & $0.64(0.48)$ & $0.65(0.48)$ & $-0.04(0.07)$ & $-0.03(0.08)$ \\
\hline $\begin{array}{l}\text { Knows that it is better to build a } \\
\text { simple string trellis with just one twine }\end{array}$ & $0.59(0.49)$ & $0.58(0.50)$ & $0.58(0.50)$ & $0.02(0.06)$ & $0.01(0.06)$ \\
\hline
\end{tabular}

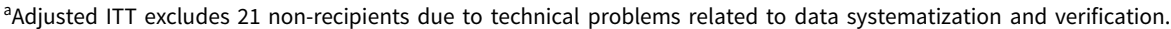

Notes: For columns (1), (2), and (3), the means and standard deviations (in parenthesis) of each knowledge question in the treatment and control groups are reported. In columns (4) and (5), the differences were calculated using the following regression: $y_{\text {ICM_practice }}=\alpha$ treatment $+\mu_{i}$. Clustered standard errors are reported in parentheses. Significance levels: ${ }^{\star} 10 \%$, ${ }^{\star \star} 5 \%$, and ${ }^{\star \star \star \star} 1 \%$. 
etc., are, at least in part, responsible for a limited adoption of ICM technologies. These factors affect on-farm costs and benefits of adoption. In this study, some practices are widely adopted. Virtually all farmers, whether in treatment or control groups, prune during the production season and eliminate weeds. This can be indicative of the success of this practice in maintaining yields. Some non-IPM practices may be perceived by farmers as relatively complex, and the benefits may not be clearly observable. For example, the benefits of building a simple string trellis do not emerge immediately, and only become apparent during harvest. This practice allows plants to grow more branches, resulting in higher yields. According to Franco et al. (1996), crop yields can be doubled by using this technique. Even though the benefits of implementing this practice outweigh the costs by a large margin (Franco et al., 1996), if those gains are not realized by the farmer who bears the costs, the voluntary adoption of such practice may not occur or may take a long time.

A common feature of the three practices mentioned above is simplicity. It may be the case that farmers adopt simpler elements of the technology first on a trial basis and will add others later as the users either change their perceptions of risks and benefits or as they acquire resources needed for the adoption (i.e. labor, information, land, and credit) of additional components of the package.

Overall, statistically, a significant difference in the adoption of only one of four cultural IPM practices can be attributed to the knowledge-building effect of text messages. Given the small and non-significant effect of treatment on knowledge, the impact of the intervention should be attributed mostly to the reminder effect of text messages.

\subsection{Multivariate regression analyses}

\subsubsection{Adoption of non-IPM practices}

The comparison of means is complemented with multivariate regression analyses. In order to provide a more intuitive understanding of the factors affecting adoption of ICM, the incident rate ratios (irr) of the Poisson regression are presented in Table 7. These are obtained by exponentiating the Poisson regression coefficient and represent the effects on the count of outcomes of a one-unit change in $x_{i}$ with all of the variables in the model held constant.

The dependent variable is the count of adopted non-IPM practices (0-5). Equation (1) includes the covariates treatment, age, age-squared, gender, a formal secondary education dummy variable, blackberry farming experience, household size, wealth, and area per capita planted with blackberry. Equation (2) adds a dummy variable representing treated farmers who did not receive text messages due to technical problems related to data systematization and verification. This variable is included to account for the fact that farmers in this group are less likely to adopt ICM. Equation (3) adds the interaction of education and treatment to explore whether text message differently affects farmers with different levels of education.

In equations (1) and (2), none of the variables is significant. In equation (3), where the interaction term is included, the coefficients for treatment becomes significant. The intervention increases the expected number of non-IPM practices adopted by a factor of 1.12, or equivalently, it increases the expected number of practices adopted by $12 \%{ }^{5}$

The equation chi-squares indicate that all three equations explain significant variance in the adoption of non-IPM practices. In equation (2) we argue that treated farmers who did not receive text messages due to technical problems related to data systematization and verification are less likely to adopt IPM. The results do not support this hypothesis as the coefficient of noncompliance is not significant. In equation (3), we hypothesized that treatment differently affects farmers with and without secondary education. The coefficient of interaction of treatment with education is not significant, giving no support to such hypothesis. For further confirmation, we conducted a likelihood ratio test, ${ }^{6}$ comparing the likelihood functions of equations (1) and (3).

\footnotetext{
${ }^{6} \operatorname{LR} \chi^{2}(2)=0.96$; Prob $>\chi^{2}=0.62$.
} 
Table 7. Poisson regression results—non-IPM practices

\begin{tabular}{|c|c|c|c|}
\hline \multirow[b]{2}{*}{ Variables } & \multicolumn{3}{|c|}{ Poisson } \\
\hline & $(1)$ & (2) & (3) \\
\hline \multicolumn{4}{|c|}{ Dependent variable: adoption of non-IPM practices (1-5) } \\
\hline \multirow[t]{2}{*}{ Treated } & 1.057 & 1.070 & $1.121^{\star \star}$ \\
\hline & $(0.053)$ & $(0.053)$ & $(0.065)$ \\
\hline \multirow[t]{2}{*}{ Age } & 1.005 & 1.005 & 1.004 \\
\hline & $(0.011)$ & $(0.011)$ & $(0.010)$ \\
\hline \multirow[t]{2}{*}{ Age-squared } & 1.000 & 1.000 & 1.000 \\
\hline & $(0.000)$ & $(0.000)$ & $(0.000)$ \\
\hline \multirow[t]{2}{*}{ Education } & 0.964 & 0.960 & 1.027 \\
\hline & $(0.042)$ & $(0.042)$ & $(0.066)$ \\
\hline \multirow[t]{2}{*}{ Gender } & 1.041 & 1.043 & 1.033 \\
\hline & $(0.044)$ & $(0.045)$ & $(0.045)$ \\
\hline \multirow[t]{2}{*}{ Blackberry farming experience } & 1.003 & 1.003 & 1.003 \\
\hline & $(0.003)$ & $(0.003)$ & $(0.003)$ \\
\hline \multirow[t]{2}{*}{ Household size } & 1.012 & 1.010 & 1.011 \\
\hline & $(0.013)$ & $(0.014)$ & $(0.014)$ \\
\hline \multirow[t]{2}{*}{ Wealth } & 1.006 & 1.006 & 1.006 \\
\hline & $(0.013)$ & $(0.013)$ & $(0.012)$ \\
\hline \multirow[t]{2}{*}{ Area per capita planted with blackberry } & 1.052 & 1.049 & 1.039 \\
\hline & $(0.137)$ & $(0.136)$ & $(0.135)$ \\
\hline \multirow[t]{2}{*}{ Did not receive the SMS } & & 0.923 & 0.915 \\
\hline & & $(0.055)$ & $(0.054)$ \\
\hline \multirow[t]{2}{*}{ Treatment $\times$ education } & & & 0.882 \\
\hline & & & $(0.076)$ \\
\hline \multirow[t]{2}{*}{ Constant } & $2.726^{\star \star \star}$ & $2.741^{\star \star \star}$ & $2.681^{\star \star \star}$ \\
\hline & $(0.763)$ & $(0.774)$ & $(0.758)$ \\
\hline Model $\chi^{2}$ & $16.73^{\star}$ & $19.12^{\star *}$ & $19.77^{\star *}$ \\
\hline Sample size & 229 & 229 & 229 \\
\hline
\end{tabular}

Notes: Significance levels: ${ }^{\star} 10 \%$, ${ }^{\star \star} 5 \%$, and ${ }^{\star \star \star} 1 \%$. Clustered standard errors in parentheses.

This test statistic shows that non-compliance and interaction term do not increase the explanatory power relative to equation (1). These results suggest that equation (1) fits the data better. In accordance with mean comparison results, we conclude that treatment does not lead to significant differences in the adoption of non-IPM practices.

\subsubsection{Adoption of IPM practices}

We report the irr of Poisson regression in Table 8. The dependent variable, adoption of IPM practices, is the aggregation of the number of cultural IPM practices adopted added to the raw count of 
Table 8. Poisson regression results_IPM practices

\begin{tabular}{|c|c|c|c|}
\hline \multirow[b]{2}{*}{ Variables } & \multicolumn{3}{|c|}{ Poisson } \\
\hline & (1) & $(2)$ & (3) \\
\hline \multicolumn{4}{|l|}{ Dependent variable: adoption of IPM practices } \\
\hline \multirow[t]{2}{*}{ Treated } & 1.095 & $1.135^{\star}$ & $1.249^{\star \star}$ \\
\hline & $(0.076)$ & $(0.078)$ & $(0.115)$ \\
\hline \multirow[t]{2}{*}{ Age } & 1.013 & 1.013 & 1.012 \\
\hline & $(0.011)$ & $(0.013)$ & $(0.013)$ \\
\hline \multirow[t]{2}{*}{ Age-squared } & 1.000 & 1.000 & 1.000 \\
\hline & $(0.000)$ & $(0.000)$ & $(0.000)$ \\
\hline \multirow[t]{2}{*}{ Education } & $1.176^{\star \star \star}$ & $1.162^{\star \star}$ & $1.320^{\star \star \star}$ \\
\hline & $(0.068)$ & $(0.068)$ & $(0.118)$ \\
\hline \multirow[t]{2}{*}{ Gender } & 1.033 & 1.039 & 1.019 \\
\hline & $(0.057)$ & $(0.058)$ & $(0.056)$ \\
\hline \multirow[t]{2}{*}{ Blackberry farming experience } & 0.997 & 0.998 & 0.998 \\
\hline & $(0.004)$ & $(0.004)$ & $(0.004)$ \\
\hline \multirow[t]{2}{*}{ Household size } & 0.995 & 0.991 & 0.992 \\
\hline & $(0.019)$ & $(0.019)$ & $(0.018)$ \\
\hline \multirow[t]{2}{*}{ Wealth } & $1.037^{\star \star \star}$ & $1.037^{\star \star \star}$ & $1.038^{\star \star \star}$ \\
\hline & $(0.014)$ & $(0.013)$ & $(0.013)$ \\
\hline \multirow[t]{2}{*}{ Area per capita planted with blackberry } & 1.096 & 1.098 & 1.078 \\
\hline & $(0.179)$ & $(0.181)$ & $(0.173)$ \\
\hline \multirow[t]{2}{*}{ Did not receive the SMS } & & $0.769^{\star \star \star}$ & $0.757^{\star \star \star}$ \\
\hline & & $(0.074)$ & $(0.071)$ \\
\hline \multirow[t]{2}{*}{ Treatment $\times$ education } & & & $0.794^{\star \star}$ \\
\hline & & & $(0.089)$ \\
\hline \multirow[t]{2}{*}{ Constant } & $2.592^{\star \star \star}$ & $2.633^{\star \star \star}$ & $2.496^{\star \star \star}$ \\
\hline & $(0.892)$ & $(0.886)$ & $(0.840)$ \\
\hline Model $\chi^{2}$ & $32.95^{\star \star \star}$ & $38.71^{\star \star \star}$ & $42.12^{\star \star}$ \\
\hline Sample size & 229 & 229 & 229 \\
\hline
\end{tabular}

Source: Regression results from the study. Significance levels: ${ }^{\star} 10 \%,{ }^{\star *} 5 \%$, and ${ }^{\star * *} 1 \%$. Clustered standard errors in parentheses.

recommended low-toxicity pesticides and fertilizers used by each farmer. Equation (1) includes the same covariates used in the regression for non-IPM practices. Equation (2) adds a dummy variable representing treated farmers who did not receive text messages due to technical problems related to data systematization and verification. Equation (3) adds the interaction of education with the treatment.

In all three equations, education and wealth are significant. In equations (1) and (2) we observe that farmers with complete secondary education adopt $18 \%$ and $16 \%$ more IPM practices than farmers with elementary or incomplete secondary education, respectively. Wealthier farmers 
Table 9. Average marginal effects - treatment and education variables

\begin{tabular}{cccc}
\hline & \multicolumn{2}{c}{ Secondary education } \\
\cline { 2 - 3 } & & 0 & 1 \\
\hline & 0 & $3.08^{* \star *}(0.22)$ & $4.07^{\star \star *}(0.32)$ \\
\hline Treatment & 1 & $3.85^{\star \star *}(0.27)$ & $4.03^{\star \star *}(0.18)$ \\
\hline
\end{tabular}

Source: Regression results from the study. Significance levels: * $10 \%,{ }^{\star \star} 5 \%$, and ${ }^{\star \star \star} 1 \%$. Clustered standard errors in parentheses.

are more likely to adopt IPM practices. This reflects the fact that richest blackberry farmers have more access to resources and may be more able to take the risk. Being a part of the treatment is a significant positive predictor of adoption of IPM practices only when the effect of controllable non-compliance is included (equation 2), meaning that if non-compliance were ignored, we would underestimate the effect of receipt of text messages on IPM adoption. The estimated coefficient for the variable that represents people who were treated but failed to receive text messages due to technical problems related to data systematization and verification is approximately $-24 \%$, meaning that failure to receive the message is associated with lower adoption.

In equation (3), the coefficients for treatment and education are not the main effects but are conditional effects. The effect of education on adoption is calculated by computing the derivative of the adoption equation with respect to education. The effect of treatment on adoption represents a change in the intercept. Among farmers with secondary education, the intervention has no impact on adoption. To better understand the effect of intervention on groups with different education levels, we present marginal effects of the treatment and education variables in Table 9. We perform Wald tests for equality of the marginal values presented in this table. The Wald test on untreated farmers (treatment $=0$ ) reveals that we can reject the hypothesis that these estimates are equal. More educated farmers in the control group adopt more IPM practices. However, the results concerning treated farmers indicate that intervention has a positive effect only among farmers without secondary education. On average, less-educated treated farmers adopted 0.77 more IPM practices compared to less-educated farmers in the control group. Among farmers with complete secondary education, the adoption of IPM practices stays the same (with an average marginal effect of 4.07 and 4.03 IPM practices) regardless of intervention. In other words, text messages have no effect on the adoption of IPM practices for well-educated farmers.

We again conducted likelihood ratio tests ${ }^{7}$ comparing the likelihood functions of equations (1) and (3) in Table 7. Test statistics show that the addition of interaction term and non-compliance variable increases the explanatory power. For the adoption of IPM practices, equation (3) fits the data better.

In summary, treatment leads to increased adoption of IPM practices. Non-compliance is a major threat to obtaining power to detect the intervention effect and, in the case at hand, should not be ignored.

\subsubsection{The effect of intervention on knowledge}

The values of irr of Poisson regression are presented in Table 10. The overall knowledge score is based on a total of five knowledge questions and reflects the number of correctly answered knowledge questions, measured on a $0-5$ scale. Equation (1) includes the co-variates such as treatment, age, a formal education dummy variable, and experience. Equation (2) adds a dummy variable representing treated farmers who did not receive text messages due to technical problems related to data systematization and verification. Equation (3) adds education/treatment interaction.

${ }^{7} \operatorname{LR} \chi^{2}(2)=7.21 ;$ Prob $>\chi^{2}=0.03$ 
Table 10. Poisson regression results_-knowledge

\begin{tabular}{|c|c|c|c|}
\hline \multirow[b]{2}{*}{ Variables } & \multicolumn{3}{|c|}{ Poisson } \\
\hline & (1) & $(2)$ & (3) \\
\hline \multicolumn{4}{|c|}{ Dependent variable: knowledge score on a 0-5 scale } \\
\hline \multirow[t]{2}{*}{ Treated } & 1.051 & 1.064 & 1.211 \\
\hline & $(0.08)$ & $(0.08)$ & $(0.10)$ \\
\hline \multirow[t]{2}{*}{ Age } & $1.005^{\star \star}$ & $1.005^{\star \star}$ & $1.006^{\star *}$ \\
\hline & $(0.00)$ & $(0.00)$ & $(0.00)$ \\
\hline \multirow[t]{2}{*}{ Education } & $1.208^{\star \star \star}$ & $1.204^{\star \star \star}$ & $1.442^{\star \star \star}$ \\
\hline & $(0.06)$ & $(0.06)$ & $(0.10)$ \\
\hline \multirow[t]{2}{*}{ Blackberry farming experience } & 1.000 & 1.000 & 1.001 \\
\hline & $(0.00)$ & $(0.00)$ & $(0.00)$ \\
\hline \multirow[t]{2}{*}{ Did not receive the SMS } & & 0.928 & 0.903 \\
\hline & & $(0.09)$ & $(0.09)$ \\
\hline \multirow[t]{2}{*}{ Education $\times$ treatment } & & & 0.724 \\
\hline & & & $(0.07)$ \\
\hline \multirow[t]{2}{*}{ Constant } & $2.098^{\star \star \star}$ & $2.099^{\star \star \star}$ & $1.885^{\star \star \star}$ \\
\hline & $(0.26)$ & $(0.26)$ & $(0.24)$ \\
\hline Model $\chi^{2}$ & $17.06^{\star \star \star}$ & $16.98^{\star \star \star}$ & $29.16^{\star \star \star}$ \\
\hline Sample size & 229 & 229 & 229 \\
\hline
\end{tabular}

Significance levels: ${ }^{\star} 10 \%,{ }^{\star \star} 5 \%$, and ${ }^{\star \star \star} 1 \%$. Clustered standard errors in parentheses.

The receipt of text messages does not have an impact on the knowledge score. In all three equations, the education coefficient is statistically significant with a large impact on knowledge. Having completed secondary education increases the expected knowledge score by a factor of 1.21 and 1.20 in equations (1) and (2); or equivalently, it increases the expected knowledge score by $21 \%$ and $20 \%{ }^{8}$ Having not received text messages due to technical problems related to data systematization and verification (when assigned to the treatment group) is not associated with knowledge. The likelihood ratio test ${ }^{9}$ leads to the conclusion that equation (1) fits the data significantly better than equation (3).

In line with the results discussed in Section 5.1.2, we observe that the intervention has a small but no significant effect on knowledge. These results suggest that messages, as sent in this study, do not have a knowledge-building effect.

\section{Conclusions}

Blackberry farmers in Ecuador face challenges, and some can be addressed by providing additional information. Farmer's knowledge and its application in a timely manner are critical determinants of farm productivity. Despite evidence that ICM is profitable for blackberry producers, the adoption is not widespread. Farmers may be inattentive to management sequencing and to the daily

\footnotetext{
${ }^{8}$ This result is derived from the following calculation: 100 (1.21-1) and $100(1.20-1)$.

${ }^{9} \mathrm{LR} \chi^{2}(2)=4.22$; Prob $>\chi^{2}=0.12$.
} 
tasks necessary for improving their productive processes. They may forget what they have learned during training or may not have been adequately trained.

The results of this paper lend support to the idea that insights from psychology and behavioral economics have the potential to enhance the impact of agricultural training. Addressing specific psychological determinants of behavioral change increases the probability of adoption of some practices. Text messages sent to farmers affected their knowledge and their ability to remember the timing of certain activities. As providers of information, text messages have a small knowledge-building effect leading to the adoption of one IPM cultural practice-disposal of pruned plant material. As reminders, text messages effectively increase the adoption of practices, especially those that have an immediate observable effect such as pesticides. The intervention was effective in increasing the adoption among less-educated individuals, evidence that text messages increased farmers' knowledge. It had no effect on the adoption of non-IPM practices. This may be because such practices do not yield an immediate result and are also labor-demanding.

The results show that text messages as task reminders have a larger effect on the adoption of ICM compared to text messages as providers of information. Given their low cost, messages are still cost-effective, even though their impact may be small. The nature of our experiment limits the extrapolation of its results to the whole population of blackberry farmers in the provinces of Tungurahua and Bolívar and to other areas. However, we believe that this approach is replicable and can be successfully implemented in different settings and crops. The intervention was implemented and evaluated during one blackberry growing season. Hence, it was not possible to ascertain the long-run effects of text messages. We suggest that, due to the marginal costs that approach zero, messaging be implemented and tested over longer periods and that field days and other training events be accompanied by a text message program. INIAP scientists are embracing some of these recommendations and taking advantage of ICT to reinforce other types of training.

Many intended recipients of messages (assigned to the treatment group) did not, for one reason or another, receive the messages. Non-compliance is a major threat to obtaining power to detect the intervention effect. In our case, it was caused, in part, by technical glitches. To reduce the rates of failure of receipt of messages, we suggest future researches undertake upfront verification to ensure reliability. One possibility would be to send a text message at the moment of enrollment, when the farmer is present, to verify that information was received and understood.

Acknowledgments. The authors thank Catherine Larochelle and George W. Norton for providing insightful comments. All errors are our own.

Financial disclosure. This material is based upon work supported by the US Agency for International Development under the Cooperative Agreement No. EPP-A-00-0400016.

Conflicts of interest. None.

\section{References}

Aker, J.C., and M. Fafchamps. How Does Mobile Phone Coverage Affect Farm-Gate Prices? Evidence from West Africa. Berkeley: University of California, 2010. Internet site: http://www/.aeaweb.org/aea/2011 conference/program/retrieve.php

Akudugu, M.A., E. Guo, and S.K. Dadzie. "Adoption of Modern Agricultural Production Technologies by Farm Households in Ghana: What Factors Influence Their Decisions?” Journal of Biology, Agriculture and Healthcare 2,3(2012):1-13.

Alwang, J., V. Barrera, G. Andrango, J.M. Dominguez, A. Martinez, L. Escudero, and C. Montufar. "Value-Chains in the Andes: Upgrading for Ecuador's Blackberry Producers," Journal of Agricultural Economics 70,3(2019):705-30.

Armijo-Olivo, S., S. Warren, and D. Magee. "Intention to Treat Analysis, Compliance, Drop-Outs and How to Deal with Missing Data in Clinical Research: A Review.” Physical Therapy Reviews 14,1(2009):36-49.

Arslan, A., N. McCarthy, L. Lipper, S. Asfaw, and A. Cattaneo. "Adoption and Intensity of Adoption of Conservation Farming Practices in Zambia.” Agriculture, Ecosystems \& Environment 187(2014):72-86.

Ashraf, N., D. Karlan, and W. Yin. "Tying Odysseus to the Mast: Evidence from a Commitment Savings Product in the Philippines." The Quarterly Journal of Economics 121,2(2006):635-72. doi: 10.2307/25098802.

Badenes, M.L., and D.H. Byrne. Fruit Breeding. Vol. 8. New York: Springer Science \& Business Media, 2012. 
Beaman, L., A. BenYishay, P. Fatch, J. Magruder, and A.M. Mobarak. Making Networks Work for Policy: Evidence from Agricultural Technology Adoption in Malawi. New Haven, CT: Innovations for Poverty Action, Impact Evaluation Report 43, 2014.

Blake, G., H. Sandler, W. Coli, D. Pober, and C. Coggins. "An Assessment of Grower Perceptions and Factors Influencing Adoption of IPM in Commercial Cranberry Production.” Renewable Agriculture and Food Systems 22,02(2007):134-144.

Bonabana-Wabbi, J. "Assessing Factors Affecting Adoption of Agricultural Technologies: The Case of Integrated Pest Management (IPM) in Kumi District, Eastern Uganda.” Ph.D. dissertation, Virginia Polytechnic Institute and State University, 2002.

Brumfield, R.G., A. Rimal, and S. Reiners. “Comparative Cost Analyses of Conventional, Integrated Crop Management, and Organic Methods.” HortTechnology 10,4(2000):785.

Carrión Yaguana, V., J. Alwang, G. Norton, and V. Barrera. "Does IPM Have Staying Power? Revisiting a Potato-Producing Area Years After Formal Training Ended.” Journal of Agricultural Economics 67,2(2016):308-23.

Chaves, B., and J. Riley. "Determination of Factors Influencing Integrated Pest Management Adoption in Coffee Berry Borer in Colombian Farms." Agriculture, Ecosystems \& Environment 87,2(2001):159-77.

Cole, S., and A.N. Fernando. "The Value of Advice: Evidence from Mobile Phone-Based Agricultural Extension.” Working paper \#13-047, Harvard Business School, 2012.

Cole, D., S. Sherwood, C. Crissman, V. Barrera, and P. Espinosa. "Pesticides and Health in Highland Ecuadorian Potato Production: Assessing Impacts and Developing Responses.” International Journal of Occupational and Environmental Health 8,3(2002):182-90.

Conley, T.G., and C.R. Udry. "Learning About a New Technology: Pineapple in Ghana." The American Economic Review, 100,1(2010):35-69.

Cuyno, L.C.M., G.W. Norton, and A. Rola. "Economic Analysis of Environmental Benefits of Integrated Pest Management: A Philippine Case Study.” Agricultural Economics 25,2-3(2001):227-33. doi: 10.1111/j.1574-0862.2001.tb00203.x

Deguine, J.P., and S. Penvern. “Agroecological Crop Protection in Organic Farming: Relevance and Limits.” In: Organic Farming, Prototype for Sustainable Agricultures. Dordrecht: Springer, 2014, pp. 107-30.

De Janvry, A., G. Graff, E. Sadoulet, and D. Zilberman. "Technological Change in Agriculture and Poverty Reduction." Concept Paper for the World Development Report on Poverty and Development, University of California at Berkeley/ World Bank, 2000.

De Janvry, A., Macours, K., and Sadoulet, E. Learning for Adopting: Technology Adoption in Developing Country Agriculture, 2017.

Delgado Orellana, F. Manejo orgánico del cultivo de mora. Monografías de Ingeniería Agronómica. Universidad de Cuenca, 2012.

DellaVigna, S. "Psychology and Economics: Evidence from the Field." Journal of Economic Literature 47,2(2009):315-372.

Drechsel, P., A. Olaleye, A. Adeoti, L. Thiombiano, B. Barry, and K. Vohland (2005). Adoption Driver and Constraints of Resource Conservation Technologies in Sub-Saharan Africa. Berlin: FAO, IWMI, Humbold Universitaet, pp. 1-21.

Drost, D., G. Long, D. Wilson, B. Miller, and W. Campbell. "Barriers to Adopting Sustainable Agricultural Practices." Journal of Extension, 34,6(1996):1-6.

Duflo, E., R. Glennerster, and M. Kremer. "Using Randomization in Development Economics Research: A Toolkit." Handbook of Development Economics 4(2007):3895-962.

Dunn, G., M. Maracy, C. Dowrick, J.L. Ayuso-Mateos, O.S. Dalgard, H. Page, V. Lehtinen, et al. "Estimating Psychological Treatment Effects from a Randomised Controlled Trial with Both Non-Compliance and Loss to Follow-Up." The British Journal of Psychiatry 183,4(2003):323-31.

Dunning, T., and S. Hyde. "The Analysis of Experimental Data: Comparing Techniques." Paper presented at the Annual Meetings of the American Political Science Association, Boston, MA, 2008.

Espín Chico, M.C.. Validación de los Componentes Tecnológicos Limpio y Orgánico, con y sin Trichoderma para el manejo del cultivo de Mora de Castilla (Rubus glaucus Benth) en el cantón Cevallos, provincia de Tungurahua, 2013.

Fafchamps, M., and B. Minten. "Impact of SMS-Based Agricultural Information on Indian Farmers." The World Bank Economic Review 26,3(2012):383-414.

Feder, G., R.E. Just, and D. Zilberman. "Adoption of Agricultural Innovations in Developing Countries: A Survey." Economic Development and Cultural Change 33,2(1985):255-98. doi: 10.1086/451461.

Feder, G., R. Murgai, and J.B. Quizon. "The Acquisition and Diffusion of Knowledge: The Case of Pest Management Training in Farmer Field Schools, Indonesia." Journal of Agricultural Economics 55,2(2004):221-43.

Feder, G., and R. Slade. "The Acquisition of Information and the Adoption of New Technology". American Journal of Agricultural Economics 66,3(1984):312-20.

Fernandez-Cornejo, J. "Environmental and Economic Consequences of Technology Adoption: IPM in Viticulture." Agricultural Economics 18,2(1998):145-55.

Foster, A.D., and M.R. Rosenzweig. "Microeconomics of Technology Adoption". Annual Review of Economics, 2(2010).

Franco, G., B. Estrada, J. Gallego Duque, J. Rodríguez Osorio, G. Monroy, and B. Londoño. Agronomía del cultivo de la mora, 1996. 
Galarza, D., S. Garcés, J. Velásquez, V. Sánchez, and J. Zambrano. El cultivo de la mora en el Ecuador. Instituto Nacional de Investigaciones Agropecuarias (INIAP), 2016.

Glennerster, R., and K. Takavarasha. Running Randomized Evaluations: A Practical Guide: Princeton University Press, 2013.

Godtland, E.M., Sadoulet, E., De Janvry, A., Murgai, R., and Ortiz, O. “The Impact of Farmer Field Schools on Knowledge and Productivity: A Study of Potato Farmers in the Peruvian Andes". Economic Development and Cultural Change 53,1(2004):63-92.

Global System for Mobile Communications Association. The Mobile Economy. GSMA Intelligence 35(2018):11.

Ibrahim, K. Constraints to Agricultural Technology Adoption in Uganda: Evidence from the 2005/06-2009/10 Uganda National Panel Survey, 2013.

Kageyama, T., N. Nishikido, T. Kobayashi, Y. Kurokawa, T. Kaneko, and M. Kabuto. "Long Commuting Time, Extensive Overtime, and Sympathodominant State Assessed in Terms of Short-Term Heart Rate Variability Among Male WhiteCollar Workers in the Tokyo Megalopolis." Industrial Health 36,3(1998):209-17.

Karlan, D., M. McConnell, S. Mullainathan, and J. Zinman. "Getting to the Top of Mind: How Reminders Increase Saving." Management Science 62,12(2016):3393-3411.

Khanna, M., O.F. Epouhe, and R. Hornbaker. “Site-Specific Crop Management: Adoption Patterns and Incentives.” Review of Agricultural Economics 21,2 (1999):455-72.

Kimberly, J.R., and M.J. Evanisko. "Organizational Innovation: The Influence of Individual, Organizational, and Contextual Factors on Hospital Adoption of Technological and Administrative Innovations." Academy of Management Journal 24,4(1981):689-713.

Kumar, D., and Y. Shivay. "Modern Concepts of Agriculture: Integrated Crop Management." Unpublished manuscript, HRS Academy, 2008.

Larochelle, C., J. Alwang, E. Travis, V.H. Barrera, and J.M. Dominguez Andrade. "Did You Really Get The Message? Using Text Reminders to Stimulate Adoption of Agricultural Technologies." The Journal of Development Studies 55,4(2019):548-64.

Lipworth, W., N. Taylor, and J. Braithwaite. "Can the Theoretical Domains Framework Account for the Implementation of Clinical Quality Interventions?” BMC Health Services Research 131(2013):530.

Luh, Y.H., W.J. Jiang, and Y.N. Chien. "Adoption of Genetically-Modified Seeds in Taiwan The Role of Information Acquisition and Knowledge Accumulation.” China Agricultural Economic Review 6,4(2014):669-97. doi: 10.1108/ CAER-03-2013-0037.

Martinez, A. “Costos del Cultivo de Mora.” INIAP. Internet site: http://tecnologia.iniap.gob.ec/index.php/explore-2/mfruti/ rmora (Accessed February 25, 2016)

Martínez-García, C.G., P. Dorward, and T. Rehman. "Factors Influencing Adoption of Crop and Forage Related and Animal Husbandry Technologies by Small-Scale Dairy Farmers in Central Mexico.” Experimental Agriculture 52,1(2016):87-109.

Mauceri, M., J. Alwang, G. Norton, and V. Barrera. "Effectiveness of Integrated Pest Management Dissemination Techniques: A Case Study of Potato Farmers in Carchi, Ecuador." Journal of Agricultural and Applied Economics 39,3(2007):765.

Michie, S., M. Johnston, C. Abraham, R. Lawton, D. Parker, and A. Walker. "Making Psychological Theory Useful for Implementing Evidence Based Practice: A Consensus Approach.” BMJ Quality \& Safety 14,1(2005):26-33.

Michie, S., Johnston, M., Francis, J., Hardeman, W., and Eccles, M. "From Theory to Intervention: Mapping Theoretically Derived Behavioural Determinants to Behaviour Change Techniques.” Applied Psychology 57,4(2008):660-80.

Mugisha, J., R. Ogwal-O, W. Ekere, and V. Ekiyar. "Adoption of IPM Groundnut Production Technologies in Eastern Uganda.” African Crop Science Journal 12,4(2005):383-91.

Mullainathan, S., and E. Shafir. Scarcity: Why Having Too Little Means So Much. New York: Henry Holt and Company, 2013.

Nakasone, E. The Role of Price Information in Agricultural Markets: Evidence from Rural Peru. (Dissertation/Thesis), ProQuest Dissertations Publishing, 2014.

Olsen Jr., J.H., “The Evaluation and Enhancement of Training Transfer.” International Journal of Training and Development 2,1(1998):61.

Palis, F.G., G.R. Singleton, and M.C. Casimero. "Strengthening Research and Extension Partnership for Impact: Lessons from Case Studies.” Research to Impact: Case Studies for Natural Resource Management for Irrigated Rice in Asia. F.G. Palis, G.R. Singleton, M.C. Casimero, and B. Hardy, eds. Los Banos, Philippines: International Rice Research Institute, 2010.

Parsa, S., S. Morse, A. Bonifacio, C.B.C. Timothy, B. Condori, V. Crespo-Pérez, S.L.A. Hobbs, et al. "Obstacles to Integrated Pest Management Adoption in Developing Countries." Proceedings of the National Academy of Sciences 111,10(2014):3889-94. doi: 10.1073/pnas.1312693111.

Peugh, J.L., D. Strotman, M. McGrady, J. Rausch, and S. Kashikar-Zuck. "Beyond Intent to Treat (ITT): A Complier Average Causal Effect (CACE) Estimation Primer." Journal of School Psychology 60(2017):7-24.

Pingali, P. "Agricultural Growth and Economic Development: A View Through the Globalization Lens." Agricultural Economics 37,1(2007):1-12.

Prudent, P., S. Loko, D. Deybe, and M. Vaissayre. "Factors Limiting the Adoption of IPM Practices by Cotton Farmers in Benin: A Participatory Approach.” Experimental Agriculture 43,1(2007):113-24. 
Stern, P.C. "Information, Incentives, and Proenvironmental Consumer Behavior". Journal of Consumer Policy 22,4(1999):461-478. doi: 10.1023/A:1006211709570.

Stockwell, M.S., E. Kharbanda, R. Martinez, C.Y. Vargas, D.K. Vawdrey, and S. Camargo. "Effect of a Text Messaging Intervention on Influenza Vaccination in an Urban, Low-Income Pediatric and Adolescent Population: A Randomized Controlled Trial." JAMA 307,16(2012):1702-08. doi: 10.1001/jama.2012.502.

Taubinsky, D. Essays in Behavioral and Experimental Economics. (Dissertation/Thesis), ProQuest, UMI Dissertations Publishing, 2014.

Teklewold, H., M. Kassie, and B. Shiferaw. "Adoption of Multiple Sustainable Agricultural Practices in Rural Ethiopia." Journal of Agricultural Economics 64,3(2013):597-623. doi: 10.1111/1477-9552.12011.

Vervloet, M., A.J. Linn, J.C. van Weert, D.H. De Bakker, M.L. Bouvy, and L. Van Dijk. "The Effectiveness of Interventions Using Electronic Reminders to Improve Adherence to Chronic Medication: A Systematic Review of the Literature." Journal of the American Medical Informatics Association 19,5(2012):696-704.

Webb, T., J. Joseph, L. Yardley, and S. Michie. "Using the Internet to Promote Health Behavior Change: A Systematic Review and Meta-Analysis of the Impact of Theoretical Basis, Use of Behavior Change Techniques, and Mode of Delivery on Efficacy." Journal of Medical Internet Research 12,1(2010):e4.

Wooldridge, J.M.. Introductory Econometrics: A Modern Approach. Mason, OH: Thomson/South-Western, 2006.

Wozniak, G.D. "Joint Information Acquisition and New Technology Adoption: Late versus Early Adoption." The Review of Economics and Statistics 75,3(1993):438-45.

Yumbo, G., and M. Elvia. Diagnóstico de la situación actual de la comercialización de la mora (Rubus glaucus sp.) en el Mercado Mayorista Ambato, 2014.

Cite this article: Carrión-Yaguana VD, Alwang J, and Barrera VH (2020). Promoting Behavioral Change Using Text Messages: A Case Study of Blackberry Farmers in Ecuador. Journal of Agricultural and Applied Economics 52, 398-419. https://doi.org/10.1017/aae.2020.7 